\title{
Turning a new "page": ways to decrease the number of pages after hours without compromising patient care
}

\author{
Annette Schröder, MD, PhD \\ Walid A. Farhat, MD \\ Darius J. Bägli, MD \\ Armando J. Lorenzo, MD \\ Martin A. Koyle, MD
}

Presented in part at the Canadian Urological Association Meeting, June 29 to July 1, 2014, St. John's, Nffld.

Accepted Aug. 27, 2019

Correspondence to:

A. Schröder

Division of Urology, Main Office

Rm M299

555 University Ave

Toronto ON M5G 1X8

annette.schroeder@gmx.net

DOI: $10.1503 /$ cjs.009119
Background: Pages to house staff after hours, especially overnight, lead to interrupted sleep and fatigue the next day. Although some pages are urgent, others may not need an immediate response. In this study we aimed to identify unwarranted pages and to establish ways to reduce them.

Methods: Over 2 months, all pages to the Department of Pediatric Urology at the Hospital for Sick Children in Toronto, Canada, during call hours were documented, including the assessment of the responding physicians of their medical necessity. After analyzing the reasons for inappropriate pages, we took several steps to try to reduce them without impairing patient care. One year later, pages were tracked again to evaluate the efficacy of our interventions.

Results: In the initial measurement period, no calls from parents and approximately $50 \%$ of the in-hospital pages (15 of 36 pages from the wards, 27 of 49 pages from the emergency department, 17 of 31 pages requesting consultations, and 8 of 8 pages from the inhouse pharmacy and outside pharmacies) were considered medically urgent. The reasons for unwarranted pages were inconsistent parent teaching, lack of adequate triaging and prioritizing on the ward and lack of awareness of the structure of the on-call provisions among different services in the hospital. Several steps were taken to streamline the teaching of parents and nurses, standardize information, provide alternative means of communication within the hospital and restrict parents' access by phone to the urologist on call. One year later, the number of pages had decreased by $70 \%$.

Conclusion: Although physician coverage throughout the day and night is necessary for high-quality and safe patient care, communication with on-call physicians should be only for appropriate reasons. The provision of consistent teaching and alternative communication channels can improve patient care as well as decrease the number of after-hour pages.

Contexte : Les appels au personnel interne par téléavertisseur, surtout la nuit, perturbent le sommeil et entraînent de la fatigue le lendemain. Même si certains de ces appels sont urgents, d'autres ne nécessitent pas de réponse immédiate. Avec cette étude nous avons voulu identifier les appels par téléavertisseur qui sont injustifiés et trouver des façons d'en réduire le nombre.

Méthodes : Sur une période 2 mois, nous avons documenté tous les appels par téléavertisseur adressés durant les heures de garde au service d'urologie pédiatrique de l'Hôpital SickKids de Toronto, au Canada, et demandé aux médecins y ayant répondu d'en évaluer le bien-fondé au plan médical. Après avoir analysé les raisons des appels jugés injustifiés, nous avons adopté plusieurs mesures pour en réduire le nombre sans compromettre les soins. Un an plus tard, nous avons de nouveau comptabilisé les appels par téléavertisseur pour mesurer l'efficacité de nos interventions.

Résultats : Durant la période de mesure initiale, aucun appel des parents n'a été considéré médicalement urgent, tout comme environ $50 \%$ des appels provenant de l'hôpital même (15 appels sur 36 des unités de soins, 27 appels sur 49 du service des urgences, 17 appels sur 31 pour des demandes de consultation et 8 appels sur 8 de la pharmacie de l'hôpital ou de pharmacies de l'extérieur). Les raisons des appels injustifiés étaient entre autres incohérence dans l'enseignement aux parents, triage et priorisation inadéquats à l'unité de soin et méconnaissance des différents services de l'hôpital quant à la structure et au fonctionnement du système de garde. Plusieurs mesures ont été prises pour simplifier l'enseignement aux parents et au personnel infirmier, standardiser l'information, fournir d'autres moyens de communication dans l'hôpital même et restreindre l'accès des parents à l'urologue de garde par téléphone. Un an plus tard, le nombre d'appels avait diminué de $70 \%$.

Conclusion : Même si les médecins doivent être joignables jour et nuit pour assurer la qualité des soins et la sécurité des patients, les raisons de communiquer avec eux doivent être appropriées. Le rappel des consignes et le recours à d'autres canaux de communication peuvent améliorer les soins aux patients et réduire le nombre d'appels le soir et la nuit. 
$\mathbf{T}$ here are many points of view regarding the workload of trainees, especially when they are on call. From the trainee's perspective, call is generally perceived as an inevitable but transient required-service phase during training. In the European Union (EU), the first EU Working Time Directive was implemented in 1993. In the United States, where demanding workloads during residency were for a long time considered to be an integral component of training, the Accreditation Council for Graduate Medical Education established the first set of common work-hour standards for accredited residency and fellowship programs in July 2003, and a revision was implemented in July 2011.,1,2 Thereafter, work weeks were restricted to a maximum of 80 hours and work days to a maximum of 16 hours. Canada's National Steering Committee on Resident Duty Hours released recommendations for a nationwide reform of resident duty hours in June 2013. ${ }^{3}$

These regulations are considered to be of utmost importance in protecting physicians as well as patients, but some of the issues associated with resident duty hours remain the subject of debate. It is not only program directors who are concerned about the consequences of reductions in resident work hours: trainees worry about reduced clinical exposure and increases in their workload and in the actual hours they work as a result of the changes, especially in surgery. ${ }^{4,5} \mathrm{~A}$ possible workaround has been to establish home calls. ${ }^{6}$ However, even a small number of pages and phone calls overnight can can disrupt sleep and potentially cause fatigue. ${ }^{78}$ Numerous studies have shown that sleep loss compromises physicians' performance and well-being. ${ }^{7,9}$ Fragmented sleep can affect not only residents' and fellows' education, but also the quality of patient care when exhausted physicians are treating patients. ${ }^{10-12}$ Efforts to improve the well-being of trainees by reducing their work hours or sending them home after call may reduce their education time. ${ }^{7,13}$ Therefore, the goal must be to reduce unnecessary components of trainees' workloads rather than merely the hours they work. ${ }^{14}$

The Hospital for Sick Children in Toronto, a universityaffiliated tertiary care centre, is the largest pediatric hospital in Canada. It was our impression that the number of pages to house staff after hours was excessive and that many of these pages were not about medically urgent matters, indicating suboptimal communication and cultural issues within the organization. The purpose of this study was to assess the reasons for unnecessary pages and to make changes to reduce the number of such pages.

\section{Methods}

The Department of Pediatric Urology at the Hospital for Sick Children consists of 4 staff surgeons and 4 fellows. One or 2 urology residents at a time rotate within the program. Residents or fellows carry the first-response pager while they are on at-home call, with a regular work day to follow the next morning. This study took place between July 2013 and August 2014 and had 3 phases: phase 1 involved the initial data collection and analysis, phase 2 involved development of the innovation and phase 3 involved remeasurement to assess outcomes.

\section{Phase 1}

Call hours were 5 pm until 8 am during the week and 24 hours on weekends. From July 7 to Sept. 16, 2013, all residents and fellows recorded every page they received during call hours on a Web-based data sheet, a representative example of which is included in Appendix 1, available at canjsurg.ca/009119-a1. Recorded data included the time, source and content of the page and the duration of the call when the trainee answered the page. The responding physician also recorded their subjective impressions of the medical urgency of each page, as well as their suggestions on how that specific call could have been avoided if it appeared to be unwarranted (e.g., "better teaching"). All on-call physicians were reminded the next morning to complete their call $\log$. The contents were then analyzed to identify the causes of unwarranted pages.

\section{Phase 2}

This phase included multiple plan-do-study-act (PDSA) cycles in which participants tested various interventions to optimize the previously accepted system (e.g., by unifying the contents of parental teaching, improving communication within the hospital) with the aim of reducing unnecessary pages by $75 \%$ in the ensuing 12 -month period.

\section{Phase 3}

The data recording process in phase 1 was repeated exactly 1 year later to capture the exact parallel period of time in the calendar year, to exclude any differences in workload that might be caused by differences in vacation season and staffing throughout the academic year. This phase took place between July 7 and Aug. 26, 2014, and the same Web-based data sheet was used.

\section{Results}

\section{Phase 1}

Over 71 consecutive nights and weekends, the on-call trainees received 172 pages, the majority of which originated from within the hospital. The maximum number of pages was 15 during a weeknight and 13 during a weekend night. There were only 8 nights without any pages $(11 \%$ of nights). The mean number of pages per call shift was 2.4. Of the 172 pages, 39 (23\%) occurred after midnight. 
Table 1. Pages received by on-call urologists during phase 1 (71 d)

\begin{tabular}{|c|c|c|c|}
\hline \multirow[b]{2}{*}{ Source } & \multicolumn{3}{|c|}{ No. of pages* } \\
\hline & Total & $\begin{array}{c}\text { Received } \\
\text { after midnight }\end{array}$ & $\begin{array}{l}\text { Considered } \\
\text { unwarranted }\end{array}$ \\
\hline Wards & 36 & 7 & 21 \\
\hline $\begin{array}{l}\text { Emergency } \\
\text { department }\end{array}$ & 49 & 17 & 22 \\
\hline Consults & 31 & 4 & 14 \\
\hline In-house pharmacy & 3 & 1 & 0 \\
\hline Parents & 35 & 8 & 35 \\
\hline Outside pharmacies & 5 & 0 & 0 \\
\hline $\begin{array}{l}\text { Outside emergency } \\
\text { departments and } \\
\text { outside physicians }\end{array}$ & 9 & 2 & 0 \\
\hline $\begin{array}{l}\text { Not remembered by } \\
\text { the on-call physician }\end{array}$ & 4 & 0 & 0 \\
\hline Total & 172 & 39 & 92 \\
\hline
\end{tabular}

Table 1 lists the originating sources of pages. The inpatient wards housing patients with urology-specific conditions generated 36 pages. Of those, 7 occurred after midnight. More than $50 \%$ of the pages concerned minor issues that were not medically urgent or whose purpose was simply to report a minor issue rather than to request an answer to a specific question.

There were 80 calls from the emergency department (ED) and requests for consultations from other inpatient pediatric wards. Forty-nine calls were made from the ED, of which 17 occurred after midnight. Twenty-seven of the 49 calls were considered to have been warranted, but the remaining calls were about minor issues. At least 10 pages were precipitated by insufficient communication within the ED or were merely to inform the responding physician about a patient who had been seen and was being discharged. Thirty-one pages were made by other inpatient pediatric departments, requesting consultations. Of those, 4 were made after midnight. Fourteen of the pages concerned very minor issues of no medical urgency. Three pages came from the in-house pharmacy, regarding recent orders; 1 of these came in after midnight. Parent calls were put through by the switchboard in 35 instances, 8 after midnight. None of the calls was considered medically urgent by the responding urologist. There were 9 calls from outside pharmacies and outside EDs to discuss patients, 2 of which occurred after midnight. Five calls were from outside pharmacies. The content of 4 pages was not recalled by the physician on call.

After assessing several PDSA cycles, we grouped the pages according to the department or unit from which they originated. We then scrutinized the group of pages that were deemed unnecessary to try to determine why each of these pages had been made and where they came from. We primarily gathered this information by interviewing personnel and staff.
Pages that came from inpatient wards were frequently made shortly after the trainee had spoken to another nurse on the same ward, indicating a lack of communication between the nurses. On-call physicians were paged to report very minor issues that could have been resolved by an experienced nurse or could have waited until the next morning. Our inquiries revealed that newly hired, inexperienced nurses often refrained from consulting the charge nurse and preferred to page the physician directly. Patients were sometimes placed on wards where the staff had little experience with urologic conditions, causing nurses to page the physician because they lacked knowledge or felt insecure.

When we considered pages that were requests for consultations or that came from the hospital's ED, we found that some late-night calls were made simply to inform the urologist on call that a consult was needed the next day or that a patient had been seen and discharged from the ED. When we made further inquiries, we found that staff in other departments, particularly those whose staff work in shifts, were not aware that urology is an off-site service overnight. Furthermore, services that felt the need to convey a message to urology at the end of their shift had no reliable means of contact other than paging the urologist on call.

Not a single page from a parent was considered medically urgent; these pages merely requested reassurance or information that should have been communicated during parent teaching. Most of the calls concerned nonacute wound issues or questions about wound care, bathing or catheter-related issues. Some pages were made after midnight to inquire about the operating room schedule the next day and NPO (nothing by mouth) regulations, to ask questions about medication or to express the wish for the physician to reduce the family's wait time in the ED. There were several occasions when the urologist suggested that the parents take their child to the ED, which was declined in most cases. Other parents already knew that they should bring their child to the ED if the child had a high fever after surgery, but they asked for confirmation of that fact. Overall the impression of the physicians who received the pages was that the threshold for paging the urologist on call was extremely low. The questions asked by parents revealed inconsistencies in parent teaching. We made extensive inquiries and found that up to 7 different forms with general or specific postoperative care instructions were handed out or could be downloaded throughout the perioperative preparations. Furthermore, different advice was given by physicians, nurses in clinic, and staff of the same-day admit unit (SDAU) and postanesthesia care unit (PACU), which resulted in parents receiving too much information and being confused about several aspects of postoperative care. The only piece of advice that was consistent across all forms, all conversations, all teaching sessions and most voicemail and email 
out-of-office replies was to call the urologist on call if there was a question.

\section{Phase 2}

An action plan was formulated to address the issues that had been identified. After the plan was approved by all staff, several steps were taken to address the low-hanging fruit: teaching and communication.

Nurses on the wards were asked to prioritize and triage their questions before paging. The charge nurses on the wards were asked to implement the change on their wards. From then on, inexperienced nurses were asked to contact the charge nurse on the urology ward or, if the patient was placed on another ward, to contact the urology ward about minor issues before or instead of paging the physician and to bundle calls and pages about important but not time-sensitive issues to be made at a given time (e.g., $10 \mathrm{pm}$ ).

Efforts were made to inform the ED and other services about the structure of the urology call schedule. A group email address for the urology fellows was created; this gave other departments the opportunity to convey any nonurgent message to the service at any time, which would be responded to the next day. All services were informed that the email address was added to the contact directory.

The postoperative care instructions for parents were revised and unified and all outdated forms were removed from the places where they had previously been distributed: websites, clinics, the SDAU and the PACU. A new discharge form was created and distributed to all units, with space for detailed, specific instructions if needed (Appendix 1). Since the completion of this study, an electronic medical record system, EPIC, has been implemented in our hospital. The concept of the standardized discharge form being used in EPIC is based on the revised written form developed as a result of this study. All health care providers in contact with patients' families during the perioperative period received teaching and detailed but simplified instructions on the advice to convey to parents. Special attention was paid to teaching parents to identify situations in which their child required immediate medical attention and those that were not urgent. Parents were clearly informed that if their child required medical attention, they should take the child to see a physician either in the community or at the nearest ED.

After a transition period of several months following the implementation of the revised written and oral information for parents, the hospital's chief of communication was asked to instruct all operators to refrain from putting parents through to the urologist on call. Postdischarge calls from parents of children who had been inpatients were to be transferred to the urology ward, where the charge nurse would screen each call. All other parent calls were transferred to a newly established voicemail line, which would prompt the parents to leave a message about nonurgent matters that would be answered the next morning. Patients were advised to take their child to the nearest ED if they deemed the situation to be a medical emergency. All voicemails and emails throughout the urology department were checked, and all faculty and staff in the department were asked to change their voicemail and email out-of-office replies to conform with a standardized script. Operators were advised to continue to put through all calls from outside physicians and pharmacies.

\section{Phase 3}

In the remeasurement period the number of pages was reduced by $70 \%$. Over 53 consecutive days, 37 pages were received (Table 2). The maximum number of pages was 4 on a weeknight and 2 over a weekend. There were 25 nights without any pages. The mean number of pages per day was 0.7 . Of the 37 pages, 7 (19\%) were made after midnight.

Over 53 consecutive days, 19 pages were made from the ward, 4 of which were made after midnight. Only 1 of the pages after midnight was regarded as not urgent by the responding physician. Of the 15 pages made before midnight, 5 were considered to be nonurgent.

Of 14 pages from the ED during the recording period, only 1 was made after midnight and it was considered necessary. Of the remaining 13 pages, 5 were considered avoidable. Two consults were requested by other departments; 1 of these was made after midnight and was considered necessary. The second call was considered to be caused by insufficient communication about a known patient. Two pages came from an outside ED and pharmacy, respectively.

Table 2. Pages received by on-call urologists during phase 3 (53 d)

\begin{tabular}{lccc|} 
& \multicolumn{3}{c}{ No. of pages* } \\
\cline { 2 - 4 } Source & Total & $\begin{array}{c}\text { Received after } \\
\text { midnight }\end{array}$ & $\begin{array}{c}\text { Considered } \\
\text { unwarranted }\end{array}$ \\
\hline Wards & 19 & 4 & 6 \\
\hline $\begin{array}{l}\text { Emergency } \\
\text { department }\end{array}$ & 14 & 1 & 5 \\
\hline Consults & 2 & 1 & 1 \\
\hline In-house pharmacy & 0 & 0 & 0 \\
\hline Parents & 0 & 0 & 1 \\
\hline Outside pharmacies & 1 & 0 & 1 \\
\hline $\begin{array}{l}\text { Outside emergency } \\
\text { departments and } \\
\text { outside physicians }\end{array}$ & 1 & 1 & 0 \\
\hline $\begin{array}{l}\text { Not remembered by } \\
\text { the on-call physician }\end{array}$ & 0 & 0 & 14 \\
\hline Total & 37 & 7 & \\
\hline *The mean no. of pages per on-call period was 0.7. & & \\
\hline
\end{tabular}


Because of the restricted access, no parent calls were put through to the urologist on call during phase 3 . No patients who presented to the ED complained about the physician not being available over the phone, and the number of patients presenting to the ED did not increase.

Staff from all units involved in the revision process (particularly nurses from the PACU and SDAU) were highly appreciative of the changes and communicated frequently that their workload had decreased significantly as a consequence of the simplified and standardized processes.

\section{Discussion}

Postgraduate surgical training is demanding and it is well documented that this training is associated with long work hours and potential for fatigue. Sleep disruptions while on call can have a severe impact on trainees' performance and learning and may also affect patient safety. ${ }^{7,15-17}$ In our study we aimed to find the main reasons for unwarranted pages to house staff from various sources and to find opportunities to reduce the number of avoidable calls, which were not of benefit to patients but rather were attributable to avoidable weaknesses in organization, communication or parental teaching, that is, the inherent culture.

On the basis of our analysis of the content of the pages received during call hours, we identified a number of inconsistencies in parent teaching, as well as communication issues within the hospital, and we recognized that there was room for substantial improvement. The changes that were implemented decreased the number of pages to the urologist on call by $70 \%$. Although our initial goal had been to reduce calls by $75 \%$, we observed an encouraging rate of improvement.

As the expectation of direct (phone) access to a physician at any time is deeply embedded in the North American culture and such access is considered an important source of reassurance, the decision to eliminate this access was difficult. However, as even the most effective standardization of, and improvement in, teaching would not prevent calls that are a result of an individual's poor personal organizational skills and a "service" attitude toward the medical profession, it was decided to restrict direct phone access to the urologist on call by people who are not health care providers. This was explicitly communicated to parents during all teaching sessions.

The revisions to parent teaching also caused a culture change. In the past, the urologist on call had been available at all times, and it was overly easy to access him or her. Now, the responsibility for decision-making was - after appropriate and thorough teaching - returned to the parents. Parents were clearly informed beforehand that the decision to take their child to see a physician postoperatively had to be made by the parents, and we believe that this information greatly enhanced parents' motivation to fully absorb the information provided during teaching.

Certainly, patient care involves not only addressing the purely medical needs of patients in terms of diagnostics and treatment but also providing emotional support to families who are dealing with a child's illness. Learning how to interact with concerned parents is an important part of medical training, but there must be a balance between what is considered service and what is considered education. There is an equally important issue with regard to medical advice given over the phone: given the fact that the physican cannot examine the patient in these circumstances, he or she has to rely on the information provided by the parent. There is a risk that the information may be incomplete and biased, which may lead the physician to incorrectly interpret the severity of the symptoms, which in turn may endanger the child's wellbeing and expose the physician to litigation. Without question, giving advice over the phone cannot be considered good and responsible medical practice.

We found that $50 \%$ of the pages from in-house sources and all calls from parents were not medically urgent, as judged by the physician on call. Recently Thériault and colleagues $^{8}$ published the results of a survey conducted in a Canadian urology program and they also found that some of the pages were not medically urgent, although they found the percentage of such pages to be lower than in our study. Another recent study assessed the number and urgency of pages received by otolaryngology residents on home call. ${ }^{7}$ The residents considered almost $80 \%$ of the pages to be nonurgent. Both author groups suggested that improved teaching of medical staff and better communication might reduce the number of unnecessary pages, but at the time of publication they had not yet implemented those measures. Similarly, we concluded that improved and unified teaching benefited patient care to the same degree as the reduction of page load.

In our study, after the changes were implemented, a small number of pages that were not considered appropriate or urgent continued to be made. This is understable, given that a teaching hospital with a high turnover of trainees will always have periods with a high number of inexperienced professionals who may call out of insecurity. It is important to stress to new trainees that when they are in doubt, they may always call.

Although the initial intention of the project was merely to reduce the number of unnecessary pages, we noticed a number of additional benefits from the changes that were made. Not only did the streamlining process substantially decrease the workload of the trainees on call, it also produced benefits for patient care. Although we did not measure the impact of the changes on the workload of the nursing and administrative staff, it was communicated to us that they experienced a positive impact as well. 
Residents and fellows tend to soldier through what is considered an unavoidable stage of very hard work, ${ }^{9}$ which will pass. Traditionally they either "suffer in silence" or complain, but most do not act to make improvements. The chief of our department (M.A.K.), who was tired of hearing the complaints, encouraged the fellows to do something about their situation, and the group effort led to a significant improvement for the next generation of residents and fellows. The issues we encountered in our hospital may be specific to this setting, but the principle of identifying and addressing weaknesses in the organizational set-up to improve work conditions is applicable to any unit.

\section{Limitations}

There are limitations to our study. Although our second measurement period (phase 3) was at exactly the same time of year as the first measurement period (phase 1), we cannot exclude the possibility that coincidentally there may have been fewer emergencies during the second period. In addition, the second measurement period was 6 weeks in duration instead of 10. However, the decrease in the number of pages from 2.4 to 0.7 per on-call period was substantial. Two fellows who were present in both the year before the innovation and the year after confirmed that the marked reduction in the number of calls remained stable over time. Unlike Caulley and colleagues, ${ }^{7}$ we did not provide the physicians on call with guidelines on how to categorize calls with regard to urgency at the start of the study; we left that assessment to the discretion of the physician on call, which may have biased the results. However, as the vast majority of calls were covered by fellows, who were certified urologists, we believe that their assessment can be considered accurate.

\section{Conclusion}

This study indicates that excessive workloads during training may not to be inevitable. Instead, they may be the result of correctable inefficiencies within the organization or issues with the organization's culture. By identifying and correcting such issues, the strain on on-call physicians can be substantially reduced. Staff and trainees can take the initiative to identify and correct deficiencies within the system to optimize the education and well-being of trainees without compromising patient care.

Acknowledgements: The authors thank the fellows of the Department of Pediatric Urology and the rotating residents of the Division of Urology, University of Toronto for logging the pages, as well as the nursing staff of the Department of Pediatric Urology for their support during the implementation of the numerous changes.
Affiliations: From the Department of Urology and Pediatric Urology, University Medical Center, Johannes Gutenberg University of Mainz, Mainz, Germany (Schröder); and the Department of Urology, Hospital for Sick Children, Toronto, Ont. (Farhat, Bägli, Lorenzo, Koyle).

\section{Competing interests: None declared.}

Contributors: All authors designed the study. A. Schröder and W. Farhat acquired the data, which all authors analyzed. A. Schröder, W. Farhat and M. Koyle wrote the article, which D. Bägli, A. Lorenzo and M. Koyle critically reviewed. All authors approved the final article for publication.

\section{References}

1. Philibert I, Friedmann P, Williams WT, et al. New requirements for resident duty hours. FAMA 2002;288:1112-4.

2. Nasca TJ, Day SH, Amis ES, et al. The new recommendations on duty hours from the ACGME Task Force. N Engl 7 Med 2010;363:e3.

3. National Steering Committee on Resident Duty Hours. Fatigue, risk and excellence: towards a pan-Canadian consensus on resident duty hours. Ottawa (ON); Royal College of Physicians and Surgeons of Canada; 2013.

4. Lachance S, Latulippe J-F, Valiquette L, et al. Perceived effects of the 16-hour workday restriction on surgical specialties: Quebec's experience. 7 Surg Educ 2014;71:707-15.

5. Richter A, Kostova P, Baur X, et al. Less work: more burnout? A comparison of working conditions and the risk of burnout by German physicians before and after the implementation of the EU Working Time Directive. Int Arch Occup Environ Health 2014;87:205-15.

6. Van Osdol AD, O'Heron CT, Jarman BT. "Same as it ever was" only different: a successful ACGME innovative project to equip PGY I residents to take at-home call. 7 Surg Educ 2014;71:e104-10.

7. Caulley L, Quimby AE, Barrowman N, et al. Effect of home-call on otolaryngology resident education: a pilot study. I Surg Educ 2017;74:228-36.

8. Thériault B, Marceau-Grimard M, Blais A-S, et al. Urology residents on call: investigating the workload and relevance of calls. Can Urol Assoc 7 2018;12:E71-5.

9. Veasey S, Rosen R, Barzansky B, et al. Sleep loss and fatigue in residency training: a reappraisal. $7 A M A$ 2002;288:1116-24.

10. Aran A, Wasserteil N, Gross I, et al. Medical decisions of pediatric residents turn riskier after a 24-hour call with no sleep. Med Decis Making 2017;37:127-33.

11. Olson EJ, Drage LA, Auger RR. Sleep deprivation, physician performance, and patient safety. Chest 2009;136:1389-96.

12. Fisman DN, Harris AD, Rubin M, et al. Fatigue increases the risk of injury from sharp devices in medical trainees: results from a case-crossover study. Infect Control Hosp Epidemiol 2007;28:10-7.

13. Henry MCW, Silverman BL, Moss RL. The impact of the 80 -hour workweek on pediatric surgical training: an Association of Pediatric Surgery Program Directors-sponsored study. 7 Pediatr Surg 2005;40:60-7; discussion 67-8.

14. Vidyarthi AR, Katz PP, Wall SD, et al. Impact of reduced duty hours on residents' educational satisfaction at the University of California, San Francisco. Acad Med 2006;81:76-81.

15. Parshuram CS, Dhanani S, Kirsh JA, et al. Fellowship training, workload, fatigue and physical stress: a prospective observational study. CMA7 2004;170:965-70.

16. Yamany T, Woldu SL, Korets R, et al. Effect of postcall fatigue on surgical skills measured by a robotic simulator. F Endourol 2015; 29:479-84.

17. Rosenbluth G, Landrigan CP. Sleep science, schedules, and safety in hospitals: challenges and solutions for pediatric providers. Pediatr Clin North Am 2012;59:1317-28. 